\title{
Processing and performance of organic insulators as a gate layer in organic thin film transistors fabricated on polyethylene terephthalate substrate
}

\author{
SAUMEN MANDAL and MONICA KATIYAR* \\ Department of Materials Science and Engineering, Samtel Centre for Display Technologies, Indian Institute of \\ Technology, Kanpur 208 016, India
}

MS received 8 May 2012; revised 17 July 2012

\begin{abstract}
Fabrication of organic thin film transistor (OTFT) on flexible substrates is a challenge, because of its low softening temperature, high roughness and flexible nature. Although several organic dielectrics have been used as gate insulator, it is difficult to choose one in absence of a comparative study covering processing of dielectric layer on polyethylene terephthalate (PET), characterization of dielectric property, pentacene film morphology and OTFT characterization. Here, we present the processing and performance of three organic dielectrics, poly(4-vinylphenol) (PVPh), polyvinyl alcohol (PVA) and poly(methyl methacrylate) (PMMA), as a gate layer in pentacene-based organic thin film transistor on PET substrate. We have used thermogravimetric analysis of organic dielectric solution to determine annealing temperature for spin-coated films of these dielectrics. Comparison of the leakage currents for the three dielectrics shows PVA exhibiting lowest leakage (in the voltage range of -30 to $+30 \mathrm{~V}$ ). This is partly because solvent is completely eliminated in the case of PVA as observed by differential thermogravimetric analysis (DTGA). We propose that DTGA can be a useful tool to optimize processing of dielectric layers. From organic thin film transistor point of view, crystal structure, morphology and surface roughness of pentacene film on all the dielectric layers were studied using X-ray diffraction (XRD), atomic force microscopy (AFM) and scanning electron microscopy (SEM). We observe pyramidal pentacene on PVPh whereas commonly observed dendritic pentacene on PMMA and PVA surface. Pentacene morphology development is discussed in terms of surface roughness, surface energy and molecular nature of the dielectric layer.
\end{abstract}

Keywords. Organic dielectric; organic thin film transistors; polyethylene terephthalate substrate; surface energy; roughness.

\section{Introduction}

From mobility point of view, organic semiconductors may never be competitors to their inorganic counterparts, but in a few applications organic semiconductors are the preferred option, e.g. flexible and transparent electronics. This is because processing on flexible substrates, viz. paper or plastic, requires temperature to be $<200^{\circ} \mathrm{C}$.

Flexible devices, such as displays (Sheraw et al 2002), inverters (Byun et al 2005; Singh et al 2006; Kim et al 2010), ring oscillators (Klauk et al 2003), logic circuits (Jeon et al 2010) have been demonstrated. Organic thin film transistor (OTFT) is one of the key components in these devices. Fabrication of OTFT on flexible substrates is a challenge, because of its low softening temperature, high roughness and flexible nature. Here, we focus on organic gate insulators used in OTFTs. Several polymeric gate insulators, such as poly(vinyl phenol) (PVPh) (Klauk et al 2002, 2003; Byun et al 2005), poly(methyl methacrylate) (PMMA) (Tunnell et al 2008), polyvinyl alcohol (PVA) (Singh et al 2005, 2006), polyimide (PI) (Ahn et al 2008, 2009), parylene

\footnotetext{
*Author for correspondence (mk@iitk.ac.in)
}

(Jakabovic et al 2009), poly(vinyl acetate) (Sung et al 2006), poly(styrene) (Liu et al 2011) and benzocyclobutene (BCB) (Sheraw et al 2000) have been used in OTFTs (table 1).

Still the selection for a given application is not easy. One requirement is that it should have high dielectric constant for low voltage operation of the OTFTs (Dimitrakopoulos and Mascaro 2001). In addition to that leakage behaviour, roughness and surface energy of the dielectric layer have strong influence on the performance of the transistor (Steudel et al 2004; Chua et al 2005). In our study, three different dielectrics were selected, crosslinked poly(vinyl phenol) (PVPh), poly(methyl methacrylate) (PMMA) and polyvinyl alcohol (PVA), because these three offer high field effect mobility of pentacene according to the literature (refer to table 1). The motivation of this study is to do a comparative evaluation of these dielectrics as a gate layer in pentacenebased OTFTs with respect to their processing temperature, dielectric constant, leakage current, surface roughness, interface quality with pentacene and pentacene morphology. We have carried out thermogravimetric analysis to determine the annealing temperature for the spin-coated films of these insulators. This is important for processing on polyethylene terephthalate (PET) substrate as maximum temperature that 
Table 1. Best reported performance of pentacene-based OTFTs using different organic layers.

\begin{tabular}{|c|c|c|c|c|c|}
\hline $\begin{array}{l}\text { Dielectric } \\
\text { material }\end{array}$ & $\begin{array}{l}\text { Mobility } \\
\left(\mathrm{cm}^{2} / \mathrm{Vs}\right)\end{array}$ & $\begin{array}{l}\text { Threshold } \\
\text { voltage (V) }\end{array}$ & $I_{\mathrm{on}} / I_{\mathrm{off}}$ & $\begin{array}{l}\text { Subthreshold } \\
\text { swing }(\mathrm{V} / \mathrm{dec})\end{array}$ & Reference \\
\hline Crosslinked PVPh & 3 & -5 & $10^{5}$ & $1 \cdot 2$ & $\begin{array}{l}\text { Klauk et al 2002, 2003; Byun et al 2005; } \\
\text { Jang and Han 2006; Xia et al } 2008\end{array}$ \\
\hline $\mathrm{PVPh}$ & $0 \cdot 5$ & 0 & & & Singh et al 2005 \\
\hline PMMA & $0 \cdot 32$ & & $2-4 \times 10^{5}$ & & $\begin{array}{l}\text { Deman et al 2008; Tunnell et al 2008; } \\
\text { Lucas et al } 2009\end{array}$ \\
\hline PI & $0 \cdot 36$ & & $2 \times 10^{5}$ & $2 \cdot 1$ & Ahn et al 2008, 2009 \\
\hline Crosslinked PVA & $0 \cdot 036$ & $-2 \cdot 9$ & $10^{5}$ & $1 \cdot 72$ & Becker et al 2003; Seo et al 2007 \\
\hline PVA & $0 \cdot 5$ & $-27 \cdot 6$ & & & Singh et al 2005, 2006 \\
\hline Parylene & $<10^{-4}$ & & & & Jakabovic et al 2009 \\
\hline PS & $0 \cdot 1$ & -30 & & & Liu et al 2011 \\
\hline Poly(vinyl acetate) & $0 \cdot 06$ & $-10 \cdot 2$ & $10^{2}$ & 10 & Sung et al 2006 \\
\hline Photoacryl & $0 \cdot 07$ & -6 & $10^{5}$ & & Kim et al 2002 \\
\hline
\end{tabular}

we can use is $180{ }^{\circ} \mathrm{C}$ without introducing curvature in the substrate.

We fabricated metal-insulator-metal (MIM) capacitor on PET substrate using PVPh, PMMA and PVA. In each case, leakage current was measured. PVA dielectric exhibits lowest leakage current which can be correlated with the differential thermogravimetric analysis. It is observed that almost zero content of the residual solvent in the PVA film is partly responsible for low leakage current.

Pentacene film, used as active material for OTFTs, was studied on each dielectric surface, as OTFT performance depends on the nature of pentacene film and its interface with the dielectric layer. It has been reported that dielectric layer's roughness (Dimitrakopoulos and Mascaro 2001) and surface energy (Yang et al 2005) are important in determining the interface quality with pentacene film. Yoon et al (2006) also correlated the interface quality of various organic semiconductors with chemical structure of the dielectric layer. Another recent report correlates OTFT performance and pentacene morphology with the surface energy or chemical structure of the dielectric (Koo et al 2009). Our results also show that pentacene morphology is affected by the dielectric layer-pyramidal morphology was observed on PVPh surface and dendritic grain along with rope-like features was noticed on PMMA and PVA surface. The rope-like features are formed due to de-wetting assisted growth in the inter-grain area as observed in the SEM image of pentacene film on PVA dielectric. Finally, OTFTs were characterized on PVPh and PMMA.

\section{Experimental}

Poly(4-vinylphenol) (PVPh), poly(methyl methacrylate) (PMMA) and polyvinyl alcohol (PVA) were chosen for this study. PVPh (10 wt\%) along with crosslinker agent (CLA) was dissolved into propylene glycol methyl ether acetate (PGMEA) solvent. PMMA (5 wt \%) and PVA (5 wt \%)

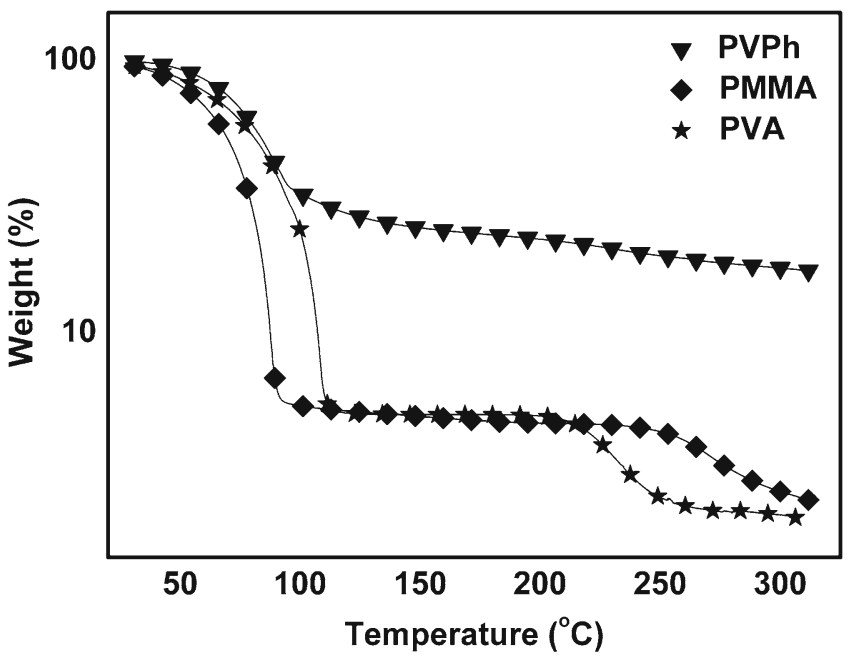

Figure 1. Thermogravimetric analysis (TGA) graph of PVPh, PMMA and PVA solution.

were dissolved in $n$-butyl acetate and DI water, respectively. Thermogravimetric analysis (TGA) of three solutions was performed at slow rate $\left(1{ }^{\circ} \mathrm{C} / \mathrm{min}\right)$ in $\mathrm{N}_{2}$ atmosphere, to observe minor thermal changes with temperature as shown in figure 1. Organic dielectric was spin coated on top of the ITO-coated PET after three-stage organic cleaning of the substrate using toluene, isopropanol and methanol. In case of PVPh system, weight percent remains $23 \%$ even at $150{ }^{\circ} \mathrm{C}$, because some amount of PGMEA are covalently attached with CLA and will not be evaporated. In case of PMMA and PVA, weight percent approaches $5 \%$ at $130{ }^{\circ} \mathrm{C}$ and $124{ }^{\circ} \mathrm{C}$, respectively. This is in agreement with the initial weight percentage used.

PVPh, PMMA and PVA were spin coated at $1000 \mathrm{rpm}$ (30 s), $2000 \mathrm{rpm}$ (40 s) and $1500 \mathrm{rpm}$ (60 s), respectively. Finally aluminum was evaporated on top of the baked dielectric film at vacuum level $<6 \times 10^{-6}$ mbar using shadow 


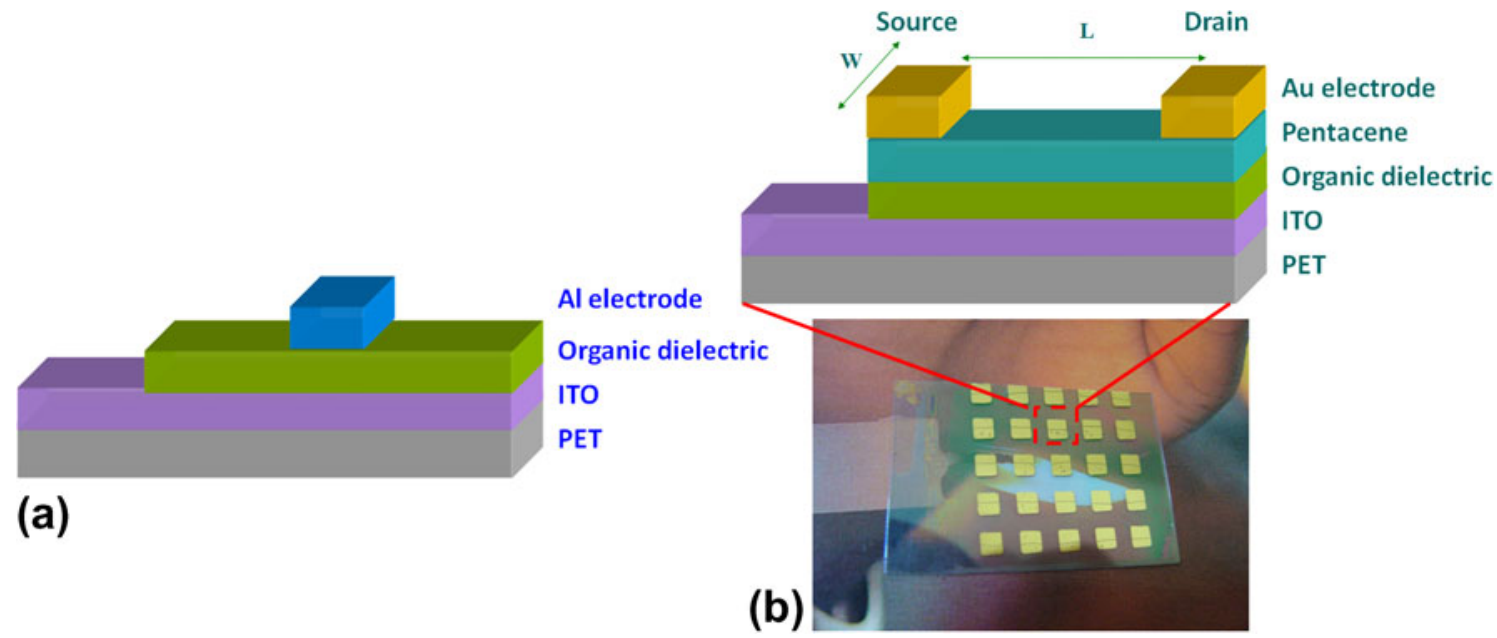

Figure 2. Schematic diagram of (a) MIM capacitor and (b) OTFT device and sample of organic transistor on PET substrate.

mask. Metal-insulator-metal capacitor was made with each organic dielectric (figure 2(a)). $C-V$ was measured by Agilent impedance analyser. Thicknesses of the dielectric films were measured using thickness profilometer. The leakage current was measured using Keithley 2602.

Top contact OTFTs were made on ITO-coated PET substrate; schematic is given in figure 2(b). Organic dielectric was spin coated on top of the cleaned ITO-coated PET substrate. Pentacene was evaporated at vacuum level $<3 \times$ $10^{-6}$ mbar on each dielectric layer. Substrate temperature and deposition rate were kept at $70{ }^{\circ} \mathrm{C}$ and $1.5 \mathrm{~nm} / \mathrm{min}$, respectively. Gold was thermally evaporated on top of the pentacene layer to make source and drain at vacuum level $<6 \times$ $10^{-6}$ mbar. The channel length and width were $50 \mu \mathrm{m}$ and $2000 \mu \mathrm{m}$, respectively. Output and transfer characteristics were studied using Keithley 2602. Output and transfer characteristics were corrected for contribution from gate current (Shih et al 2001; Zeitzoff et al 2003). Half of the gate current was added to the drain current which is the effective current through the channel. Crystallinity and surface features of pentacene films were investigated using XRD and AFM.

\section{Results and discussion}

To decide the baking temperature of the spin coated organic insulators, we have used TGA curves (figure 1). Figure 3 shows derivative of thermogravimetric analysis (DTGA) with temperature. In case of $\mathrm{PVPh}$, large peak was observed at $91.5^{\circ} \mathrm{C}$ due to the elimination of the solvent, PGMEA. The boiling point of PGMEA is $145^{\circ} \mathrm{C}$, but it starts evaporating much earlier during heating. The inset diagram of figure 3 also shows that DTGA never approaches zero, indicating all the solvent is not removed during heating up to $195^{\circ} \mathrm{C}$. But, slope is almost constant between $159{ }^{\circ} \mathrm{C}$ and $195^{\circ} \mathrm{C}$ (figure 3 inset), and this is the temperature range for baking of $\mathrm{PVPh}$,

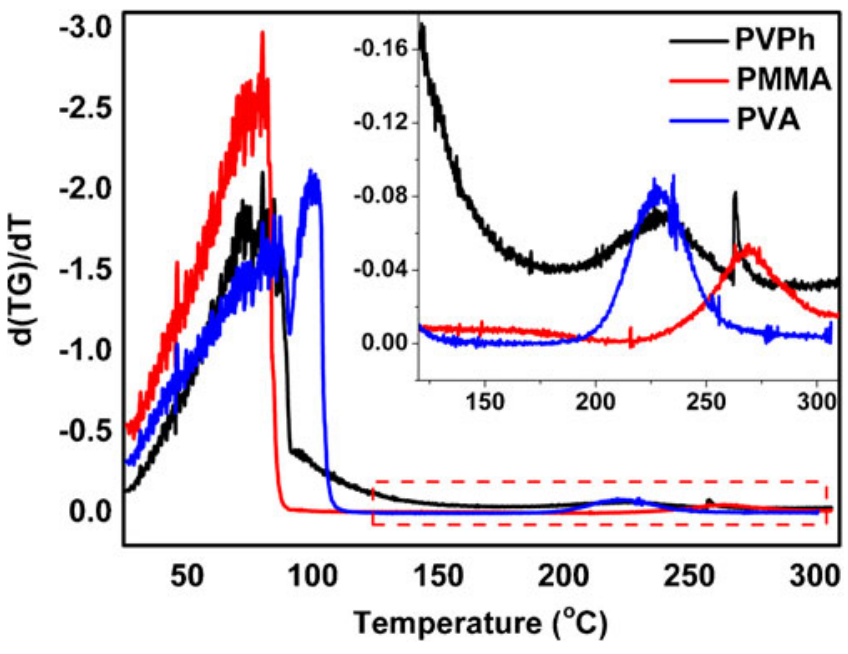

Figure 3. Derivative of thermogravimetric analysis (DTGA) graph of PVPh, PMMA and PVA solution. Inset shows detailed analysis between temperature range of $130{ }^{\circ} \mathrm{C}$ and $320^{\circ} \mathrm{C}$.

after that degradation starts which appears as a hump. Based on these results $\mathrm{PVPh}$ film was annealed at $160{ }^{\circ} \mathrm{C}$ for $1 \mathrm{~h}$.

In case of PMMA system, large peak was observed at $83.2{ }^{\circ} \mathrm{C}$. This peak is due to elimination of solvent $n$-butyl acetate. The boiling point of $n$-butyl acetate is $126^{\circ} \mathrm{C}$. DTGA curve of PMMA is constant and from $128{ }^{\circ} \mathrm{C}$ to $218^{\circ} \mathrm{C}$, it is almost zero (figure 3 ). This range will be the baking temperature zone for PMMA; after that further degradation of polymer occurs as shown by the hump in figure 3. Spin-coated PMMA films were baked at $170{ }^{\circ} \mathrm{C}$ for $1 \mathrm{~h}$.

Solvent evaporation is complicated in case of PVA system, where two peaks appear at $91.5{ }^{\circ} \mathrm{C}$ and $107{ }^{\circ} \mathrm{C}$ (figure 3). One possible explanation could be that first one is due to physically adsorbed and second one is due to chemically absorbed water in PVA. Here, slope becomes constant 
Table 2. Film thickness, roughness, capacitance and dielectric constant of organic dielectric film.

\begin{tabular}{lcccc}
\hline Dielectric & $\begin{array}{c}\text { Layer thickness } \\
(\mathrm{nm})\end{array}$ & $\begin{array}{c}\text { Roughness } \\
(\mathrm{nm})\end{array}$ & $\begin{array}{c}\text { Capacitance/area } \\
\left(\mathrm{nF} / \mathrm{cm}^{2}\right) \text { at } 100 \mathrm{kHz}\end{array}$ & $\begin{array}{c}\text { Dielectric } \\
\text { constant }\end{array}$ \\
\hline PVPh & 950 & $8 \cdot 5$ & $4 \cdot 6 \pm 0 \cdot 3$ & $5 \cdot 0$ \\
PMMA & 310 & $2 \cdot 0$ & $13 \cdot 3 \pm 0 \cdot 5$ & $4 \cdot 5$ \\
PVA & 510 & $2 \cdot 3$ & $13 \cdot 1 \pm 0 \cdot 5$ & $7 \cdot 4$ \\
\hline
\end{tabular}

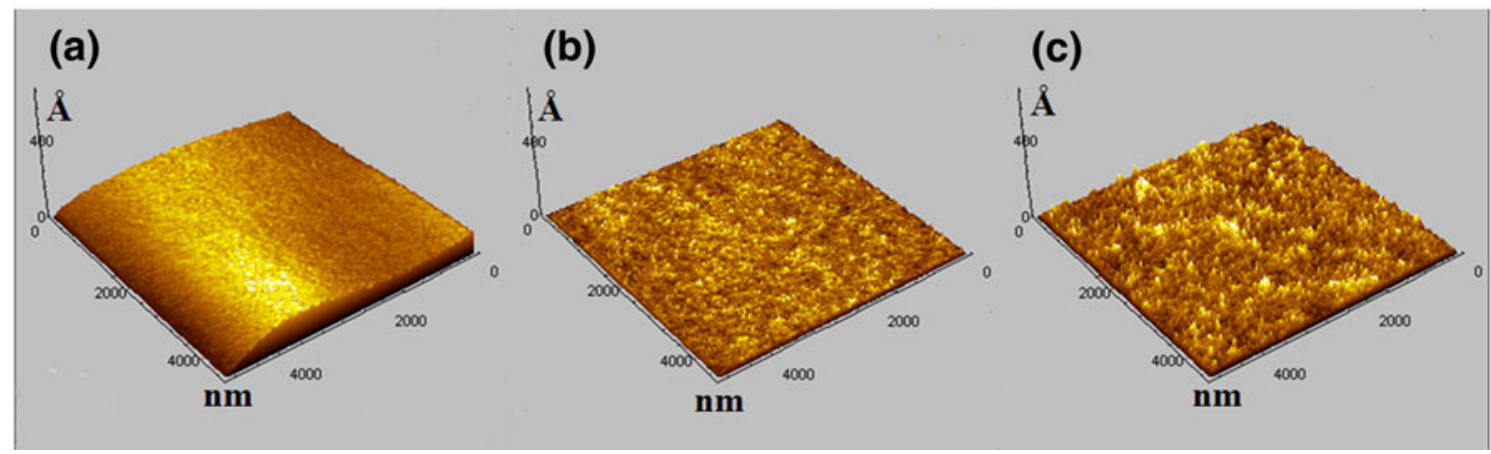

Figure 4. AFM micrograph of (a) PVPh, (b) PMMA and (c) PVA film.

and almost zero between $135^{\circ} \mathrm{C}$ and $194^{\circ} \mathrm{C}$, after that degradation starts. So, complete elimination of solvent is possible in case of PVA system. We have used two-stage baking, $110^{\circ} \mathrm{C}$ for $30 \mathrm{~min}$ followed by $140{ }^{\circ} \mathrm{C}$ for $30 \mathrm{~min}$, in case of PVA film.

Table 2 summarizes obtained thickness, roughness, capacitance and dielectric constant values of PVPh, PMMA and PVA films. The roughness was calculated using AFM analysis as shown in figure 4 , where $10 \times 10 \mu \mathrm{m}$ area was scanned. In terms of roughness, PMMA and PVA films are similar. In case of PVPh film, roughness was $8.5 \mathrm{~nm}$ due to wavy nature of the PVPh surface resulting in thickness variation in the film. If we evaluate the roughness of smaller area $(2 \times 2 \mu \mathrm{m}), \mathrm{PVPh}$ also exhibits very smooth film having a roughness of $1.5 \mathrm{~nm}$ (figure 5). All three dielectrics show similar roughness at smaller scale, hence effect of roughness is not the primary variable in deciding the dielectricpentacene interface and pentacene film morphology.

Figure 6 shows leakage current for three capacitors. PVPh and PMMA exhibit high leakage current and can be used only at low voltages. But, PVA film has minimum leakage current compared to the other two dielectric films. This can be explained with the help of differential thermogravimetric analysis (figure 3), where we observe that complete removal of solvent was obtained only in the case of PVA solution. DTGA graph also shows similar behaviour for PMMA, but leakage is more. This could be due to lower thickness of PMMA here.

Finally transistor was fabricated on top of the three dielectric surfaces. Output and transfer characteristics of OTFTs using PVPh and PMMA as dielectric layer are given in

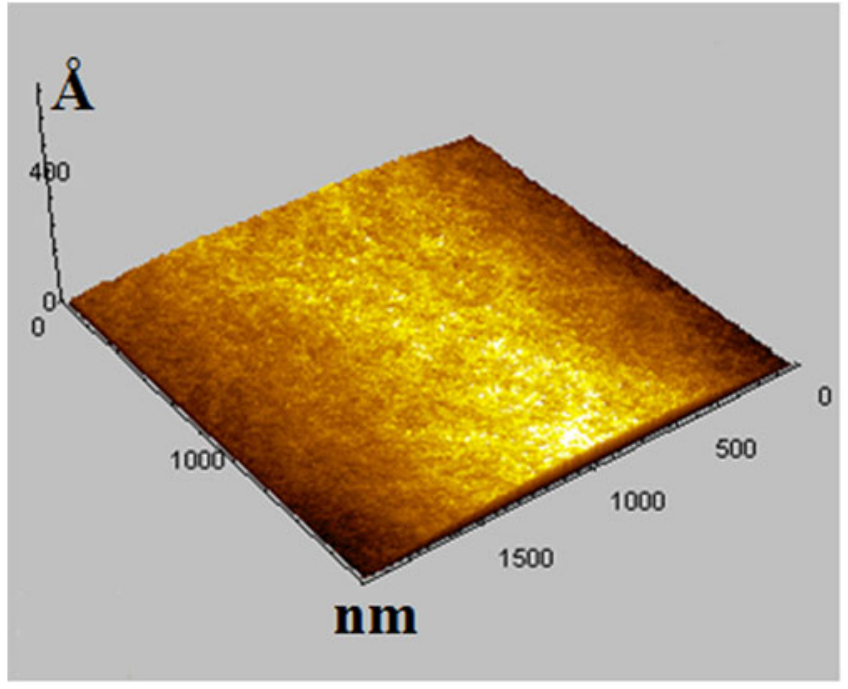

Figure 5. Small area $(2 \times 2 \mu \mathrm{m})$ AFM micrograph of PVPh film.

figure 7. And, details of the transistor characteristics are mentioned in table 3. The field-effect mobility of pentacene was four times lesser for PVPh. This can be correlated to the morphological analysis of pentacene (figure 8). The pentacene grain size is almost double on PMMA as compared to the film on PVPh dielectric. This is the reason for higher mobility of PMMA system. Details of morphological analysis are given in table 4. PVPh surface promotes compact pyramidal pentacene morphology 

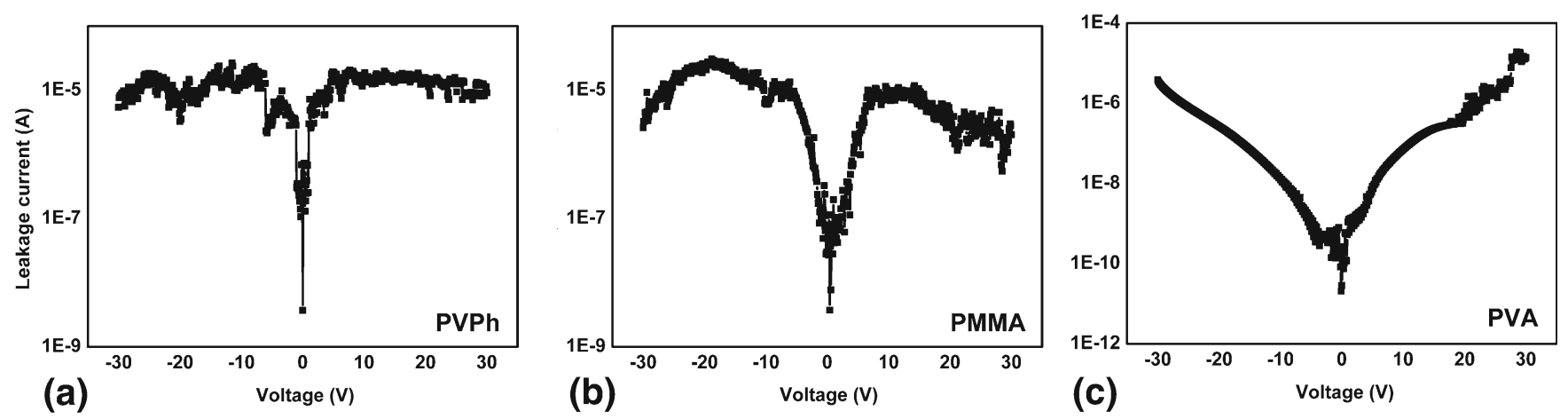

Figure 6. Leakage current studies of (a) PVPh, (b) PMMA and (c) PVA film.
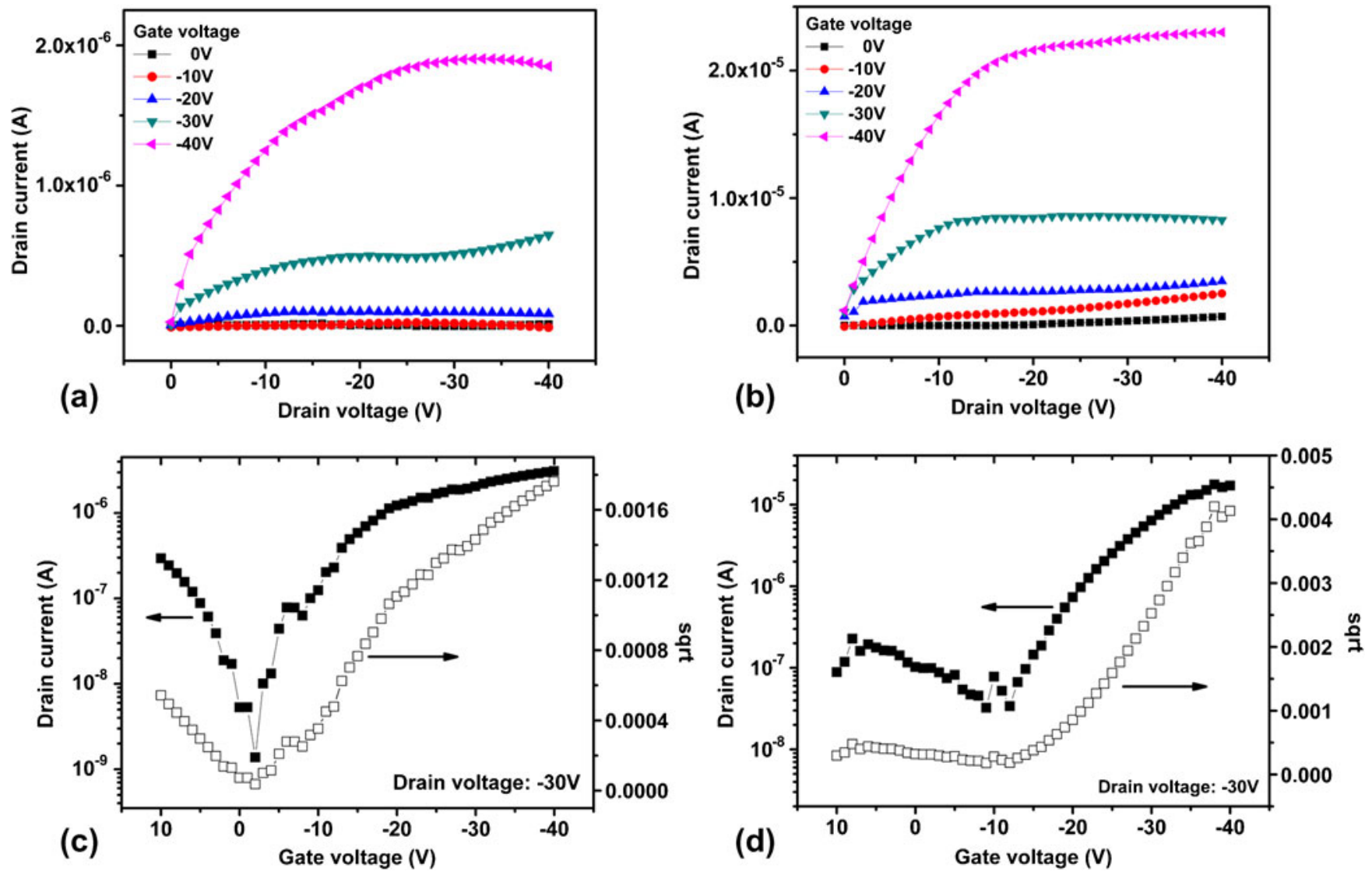

Figure 7. Output (a) and transfer (c) characteristics of PVPh-based OTFT and output (b) and transfer (d) characteristics of PMMA-based transistor.

(figures 8(a) and (d)), and dendritic pentacene morphology was observed on PMMA (figures 8(b) and (e)). Another interesting feature observed is de-wetting of pentacene on PMMA as well as PVA dielectric giving rise to large ropelike morphological features on the surface. Prominent (001) crystalline peak of pentacene film was observed on PVPh and PMMA (figures $8(\mathrm{~g})$ and $(\mathrm{h})$ ), whereas (001) peak intensity considerably deteriorates on PVA surface (figure 8(i)) due to significant de-wetting of pentacene film.
To further investigate the morphology of pentacene film on PVA surface, SEM image of pentacene film is taken (figure 9). Three different regions were observed: (i) dendritic grain region, (ii) de-wetted rope-like feature that predominantly forms in the intergranular region and (iii) PVA surface without pentacene film. Since all the dielectric films had similar roughness, the morphological changes in pentacene film can be seen as effect of the surface property of the dielectric. PMMA is most hydrophobic, followed by $\mathrm{PVPh}$ 
and PVA, water contact angle of PMMA, PVPh and PVA are $70-77^{\circ}$ (Deman et al 2008), 50 (Klauk et al 2002) and $45^{\circ}$ (Yoon et al 2006), respectively. Higher contact angle indicates lower surface energy of the dielectric surface. When depositing pentacene on $\mathrm{SiO}_{2}$ dielectric, it has been observed that dendritic morphology is formed on hydrophilic
$\mathrm{SiO}_{2}$ (high surface energy) and after surface treatment, small granular morphology is obtained on hydrophobic surface (low surface energy). In contrast to that, here we observe dendritic morphology on most and least hydrophobic dielectrics-PMMA and PVA. Further, PVPh having intermediate surface energy shows pyramidal morphology.

Table 3. Mobility, threshold voltage, $I_{\mathrm{on}} / I_{\text {off }}$ ratio and subthreshold swing (after gate leakage correction) of OTFTs.

\begin{tabular}{|c|c|c|c|c|}
\hline Dielectric & $\begin{array}{l}\text { Mobility } \\
\left(\mathrm{cm}^{2} / \mathrm{Vs}\right)\end{array}$ & $\begin{array}{c}\text { Threshold } \\
\text { voltage (V) }\end{array}$ & $I_{\mathrm{on}} / I_{\mathrm{off}}$ ratio & $\begin{array}{c}\text { Subthreshold } \\
\text { swing }(V / \text { dec })\end{array}$ \\
\hline $\mathrm{PVPh}$ & $0.03 \pm 0.01$ & $-7.2 \pm 4.2$ & $10^{3}$ & $10 \cdot 1 \pm 8$ \\
\hline PMMA & $0 \cdot 12 \pm 0.04$ & $-17 \cdot 5 \pm 2 \cdot 6$ & $10^{3}$ & $13 \cdot 6 \pm 12 \cdot 1$ \\
\hline
\end{tabular}
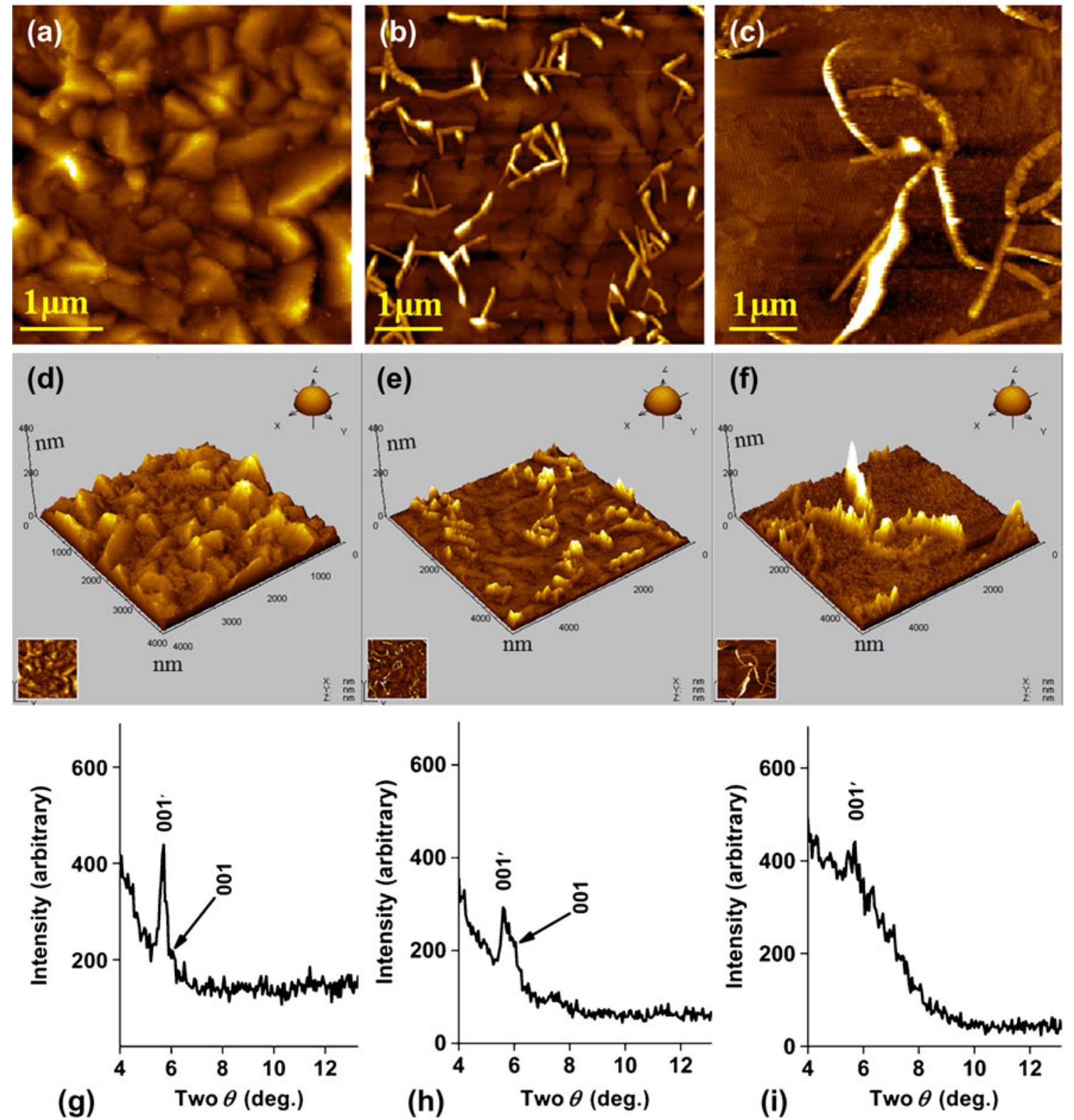

Figure 8. AFM of $50 \mathrm{~nm}$ thick pentacene film on PVPh (a) and (d), PMMA (b) and (e) and PVA surface (c) and (f). XRD of $50 \mathrm{~nm}$ pentacene film on top of (g) PVPh, (h) PMMA and (i) PVA surface. 
Table 4. Phases, morphology and grain size of pentacene films deposited on PVPh and PMMA.

\begin{tabular}{llll}
\hline Dielectric surface & Pentacene phase & Morphology & Grain size $(\mu \mathrm{m})$ \\
\hline PVPh & Thin film and bulk & Pyramidal & $0 \cdot 5 \pm 0 \cdot 1$ \\
PMMA & Thin film and bulk & Dendritic with rope-like feature & $0.9 \pm 0 \cdot 2$ \\
\hline
\end{tabular}

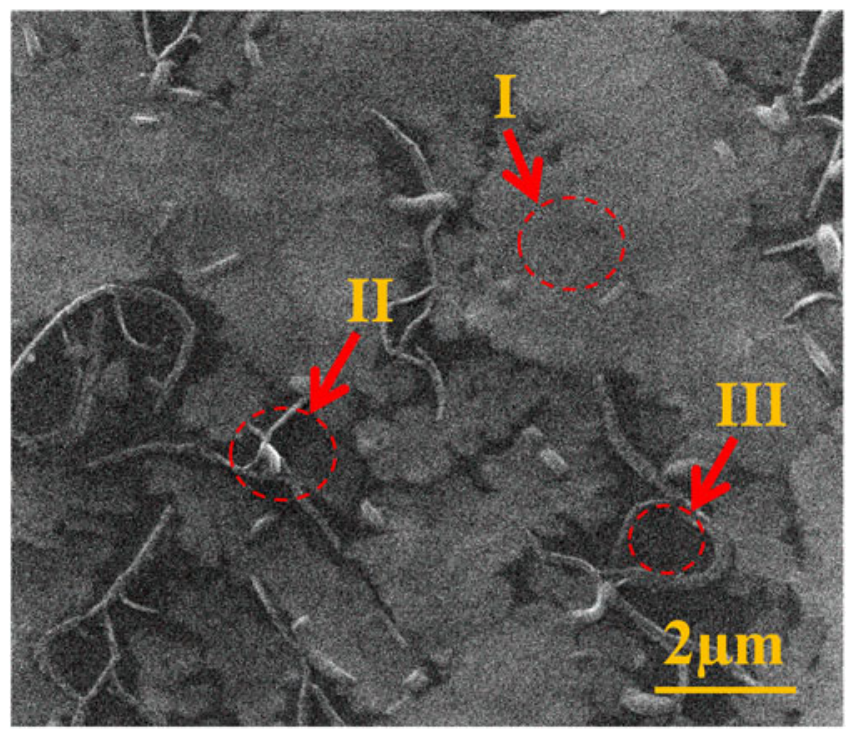

Figure 9. SEM micrograph of pentacene film on top of PVA surface, having three zones: (i) smooth film, (ii) de-wetted pentacene rope and (iii) no film zone.

In our experiments, surface energy is decreasing in the order $\mathrm{PVA}>\mathrm{PVPh}>\mathrm{PMMA}$ and in this sequence the morphology changes first from dendritic to pyramidal and then again to dendritic. This indicates that, in addition to surface energy, the molecular structure of the dielectric is also important in deciding the pentacene morphology. Comparing our results with the literature, we find different pentacene morphologies have been reported on the PVA dielectric, e.g. dendritic (Singh et al 2005; Seo et al 2007) and smooth granular morphology (Yoon et al 2006). This is because in addition to the dielectric's surface energy pentacene deposition parameters are also responsible in determining the morphology.

\section{Conclusions}

We have presented comparative studies of three organic dielectrics (spin coated) with respect to their dielectric properties and performance in an evaporated pentacene based OTFT on PET substrate. The dielectric constant obtained is 7.4, 5 and 4.5 for PVA, PVPh and PMMA, respectively. Among these, PVA exhibits minimum leakage current which could be correlated to DTGA data that shows complete removal of the solvent during baking in the case of PVA. From OTFT point of view, interface with the pentacene is important. Since roughness is similar for all dielectrics of about $2 \mathrm{~nm}$, the surface energy of the dielectric layer dictates the interface quality and morphology of the pentacene film. We find that field effect mobility of pentacene is higher in OTFT using PMMA compared to OTFTs using $\mathrm{PVPh}$, because pentacene grains are almost double in size on PMMA surface. There was significant de-wetting of pentacene on PVA surface and we were not able to get functional OTFTs. Surface treatment on PVA needs to be explored to fabricate pentacene OTFT on PVA, since leakage current for PVA is very low and there is good chance to make devices with better characteristics. We also concluded that surface energy of the dielectric is not the only parameter determining the pentacene morphology, therefore, effect of molecular nature of the dielectric layer can further be investigated.

\section{References}

Ahn T, Choi Y and Yi M H 2008 Appl. Surf. Sci. 2552185

Ahn T, Choi Y, Jung H M and Yi M 2009 Org. Electron. 1012

Becker E et al 2003 Appl. Phys. Lett. 834044

Byun H S, Xu Y X and Song C K 2005 Thin Solid Films 493278

Chua L L, Zaumseil J, Chang J F, Ou E C W, Ho P K H, Sirringhaus H and Friend R H 2005 Nature 434194

Dimitrakopoulos C D and Mascaro D J 2001 IBM J. Res. \& Dev. 45 11

Deman A L, Erouel M, Lallemand D, Goutorbe M P, Lang P and Tardy J 2008 J. Non-Cryst. Solids 3541598

Jakabovic J, Kovac J, Weis M, Hasko D, Srnanek R, Valent P and Resel R 2009 Microelectron. J. 40595

Jang J and Han S H 2006 Curr. Appl. Phys. 6S1 e17

Jeon J, Murmann B and Bao Z 2010 IEEE Electron Device Lett. 31 1488

Klauk H, Halik M, Zschieschang U, Schmid G, Radlik W and Weber W 2002 J. Appl. Phys. 925259

Klauk H, Halik M, Zschieschang U, Eder F, Schmid G and Dehm C 2003 Appl. Phys. Lett. 824175

Kim Y M, Pyo S W, Kim J S, Shim J H, Suh C H and Kim Y K 2002 Opt. Mater. 21425

Kim J B, Hernandez C F, Kim S J, Choi S and Kippelen B 2010 Org. Electron. 111074

Koo J B, Kang S Y, You I K and Suh K S 2009 Solid State Electron. 53621

Liu C, Zhu Q, Jin W, Gu W and Wang J 2011 Synth. Met. 161 1635

Lucas B, Amrani A El, Chakaroun M, Ratier B, Antony R and Moliton A 2009 Thin Solid Films 5176280

Seo J H, Kwon J H, Shin S I, Suh K S and Ju B K 2007 Semicond. Sci. Technol. 221039

Sheraw C D, Gundlach D J and Jackson T N 2000 Mater. Res. Soc. Symp. Proc. $\mathbf{5 5 8} 403$ 
Sheraw C D, Zhou L, Huang J R, Gundlach D J, Jackson T N, Kane M G, Hill I G, Hammond M S, Campi J, Greening B K, Francl J and West J 2002 Appl. Phys. Lett. 801088

Shih K W, Rios R, Packan P, Mistry K and Abbott T 2001 Device Meeting, IEDM 13.3.1

Singh T B, Meghdadi F, Gunes S, Marjanovic N, Horowitz G, Lang P, Bauer S and Sariciftci N S 2005 Adv. Mater. 172315

Singh Th B, Senkarabacak P, Sariciftci N S, Tanda A, Lackner C, Hagelauer R and Horowitz G 2006 Appl. Phys. Lett. 89033512

Steudel S, Vusser S D, Jonge S D, Janssen D, Verlaak S, Genoe J and Heremans P 2004 Appl. Phys. Lett. 854400
Sung J H, Park S J, Park J H, Choi H J and Choi J S 2006 Synth. Met. 156861

Tunnell A J, Hines D R, Nadal E G and Williams E D 2008 Org. Electron. 9507

Yang S Y, Shin K and Park C E 2005 Adv. Funct. Mater. 15 1806

Yoon M H, Kim C, Facchetti A and Marks T J 2006 J. Am. Chem. Soc. 12812851

Xia Q, Burkhardt M and Halik M 2008 Org. Electron. 91061

Zeitzoff P M, Young C D, Brown G A and Kim Y 2003 IEEE Elec. Dev. Lett. 24275 